\title{
Suppression of Ambipolar Current and Analysis of RF Performance in Double Gate Tunneling Field Effect Transistors for Low-Power Applications
}

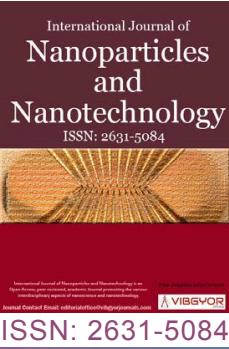

N Guenifi' ${ }^{*}$, SB Rahi' and M Larbi'

${ }^{1}$ LEA Electronics Department, University Mostefa Benboulaid of Batna 2, Algeria

${ }^{2}$ Department of Electrical Engineering, Indian Institute of Technology Kanpur, India

\begin{abstract}
The present research letter is dedicated to a detailed analysis of a double-gate tunnel field-effect transistor (DG-TFET). The DG-TFET provides improved on-current $\left(\mathrm{I}_{\mathrm{ON}}\right)$ than a conventional TFET via bandto-band (B2B) tunneling. However, DG-TFET is disadvantageous for low-power applications because of increased off-current $\left(\mathrm{I}_{\mathrm{OFF}}\right)$ due to the large ambipolar current $\left(\mathrm{I}_{\text {amb }}\right)$. In this research work, a Si/GaAs/ GaAs heterostructure DG-TFET is considered as research base for investigation of device performance. The electrical parameters of the DG-TFET device have been improved in comparison to the homostructure. The transfer (I-V) characteristics, capacitance - voltage (C-V) characteristic of homo structure Si/ $\mathrm{Si} / \mathrm{Si}$ and hetero structure $\mathrm{Si} / \mathrm{GaAs} / \mathrm{GaAs}$, DG-TFET both structures is analysed comparatively. The C-V characteristics of DG-TFET have obtained using operating frequency of $1 \mathrm{MHz}$. The ambipolar current lamb is suppressed by $5 \times 10^{8}$ order of magnitude in proposed Si/GaAs/GaAs hetero DG-TFET as compared to $\mathrm{Si} / \mathrm{Si} / \mathrm{Si}$ homo DG-TFET up to the applied drain voltage very low equal to VDS $=0.5 \mathrm{~V}$ without affecting on- state performance. The simulation result shows a very good $\mathrm{I}_{\mathrm{ON}} / \mathrm{I}_{\text {ofF }}$ ratio $\left(10^{13}\right)$ and low subthreshold slope, SS ( $36.52 \mathrm{mV} / \mathrm{dec})$. The various electrical characteristics of homo and hetero DGTFET such as on-current $\left(\mathrm{I}_{\mathrm{ON}}\right)$, off - current $\left(\mathrm{I}_{\mathrm{OFF}}\right)$, time delay $\left(\mathrm{t}_{\mathrm{d}}\right)$, transconductance $\left(\mathrm{g}_{\mathrm{m}}\right)$, and power delay product (PDP) have been improve in Si/GaAs/GaAs heterostructure DG-TFET and compared with $\mathrm{Si} / \mathrm{Si} /$ Si homo DG-TFET. The advantageous results obtained for the proposed design show its usability in the field of digital and analog applications.
\end{abstract}

\section{Keywords}

Tunnel FET, Ambipolar current, Transconductance, C-V characteristics, RF performance, LPEs, PDP

\section{Introduction}

Progress in the development of low power electronics (LPEs) is reviewed by most suitable candidate named, tunneling field effect transistor popularly named Tunnel FET [1,2]. TFETs devices have emerged as a promising candidate for future low energy electronic circuit and system design. This device has attracted attention as a candidate for low-power applications because of its low subthreshold swing (SS) and negligible off-state current $\left(\mathrm{I}_{\mathrm{OFF}}\right)$ compared with the conventional metal-oxide-semiconductor field-effect transistor (MOSFET) [3-8]. The Tunnel FET is advocated as most appropriate candidate for low power applications

*Corresponding author: N Guenifi, LEA Electronics Department, University Mostefa Benboulaid of Batna 2, Batna, 05000, Algeria

Accepted: March 16, 2020; Published: March 18, 2020

Copyright: (C) 2020 Guenifi N, et al. This is an open-access article distributed under the terms of the Creative Commons Attribution License, which permits unrestricted use, distribution, and reproduction in any medium, provided the original author and source are credited.

Guenifi et al. Int J Nanoparticles Nanotech 2020, 6:033

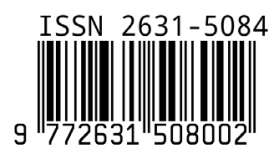


but due their comparatively lower on-current $\left(\mathrm{I}_{\mathrm{ON}}\right)$ must be improved to be compatible with future of VLSI circuit applications.

The Tunnel FET works by using modulated electric field by gate terminal, the width of tunneling barrier, instead of the height of a barrier that carriers must surmount via thermionic emission [9-12]. In TFET current transmission functions via tunneling transport mechanism, have weak temperature dependence and potential for subthreshold swing below the $\mathrm{kT} / \mathrm{q}$ thermal limit of $\sim 60 \mathrm{mV} /$ decade at room temperature [13]. TFETs devices are not plagued by the similar short channel effects as MOSFETs. Although, the drain potential can affect the tunneling barrier at very short channel lengths, a reduction in supply voltage $\left(\mathrm{V}_{D D}\right)$ enabled by the steep subthreshold swing of a TFET can likely lessen the effect. Therefore, the TFET device structure potentially allows for scaling to shorter channel lengths prolonging Moore's Law, and these properties make TFETs a candidate for ultra-low power logic applications [13-15].

Owing to its distinct operation mechanism, namely band-to-band (B2B) tunneling, tunnel field effect transistors (TFETs) can overcome the subthreshold slope (SS) limitations of conventional MOSFETs and have thus attracted substantial attention for their use in low power applications. However, silicon (Si) based tunnel FETs always suffers from a low on-state current $\left(\mathrm{I}_{\mathrm{ON}}\right)$ due large band gap (EG 1.12eV) [16-19]. Therefore various approaches have been proposed by semiconductor device players to boost the band-to-band (B2B) tunneling current, such as using lower band-gap materials at the source or fabricating TFETs with a high-k gate dielectric, with double-gate, with a high-k spacer, and with a thin epitaxial tunnel layer (ETL) $[20,21]$. Although using, a low bandgap semiconductor materials in source terminal side, the tunnel region works to increase the tunnel current $\left(I_{O N}\right)$, such devices subsequently have almost negligible off-sate current $I_{\text {OFF }}\left(\sim 10^{-18} \mathrm{~A} / \mu \mathrm{m}\right)$. The high- $\mathrm{K}$ gate dielectrics and high- $\mathrm{k}$ spacers are used to enhance the electrostatics behavior of TFET devices $[6,22-31]$.

In this work, the ambipolar current lamb is suppressed by $5 \times 10^{8}$ order of magnitude in proposed $\mathrm{Si} / \mathrm{GaAs} / \mathrm{GaAs}$ hetero DG -TFET as compared to Si/ $\mathrm{Si} / \mathrm{Si}$ homo DG-TFET up to the applied drain voltage very low equal to VDS $=0.5 \mathrm{~V}$ without affecting on-state performance. The simulation result shows a very good $\mathrm{I}_{\mathrm{ON}} /$ IOFF ratio $\left(10^{13}\right)$ and low SS ( $36.52 \mathrm{mV} / \mathrm{dec})$. The various electrical characteristics of homo and hetero structured DG-TFET such as on-current $\left(\mathrm{I}_{\mathrm{ON}}\right)$, off-current $\left(\mathrm{I}_{\mathrm{OFF}}\right)$, time delay $\left(\mathrm{l}_{\mathrm{d}}\right)$, transconductance $\left(\mathrm{g}_{\mathrm{m}}\right)$, and power delay product (PDP) have been improve for $\mathrm{Si} / \mathrm{GaAs} / \mathrm{GaAs}$ heterostructure DG-TFET and compared with $\mathrm{Si} / \mathrm{Si} / \mathrm{Si}$ homo DG-TFET.

\section{Device Analysis Procedure (DAP) and setup}

Figure 1 shows the 3D schematic view of homo and hetero structure double tunnel FET (DG-TFET), used in present research work. Figure $2 \mathrm{a}$ and Figure $2 b$ shows, the Tony plot display using $2 \mathrm{D}$ mesh of double gate homo and heterostructure based on $\mathrm{Si} / \mathrm{Si} / \mathrm{Si}$ and $\mathrm{Si} / \mathrm{GaAs} / \mathrm{GaAs}$ semiconductor material for source, channel and drain region respectively.

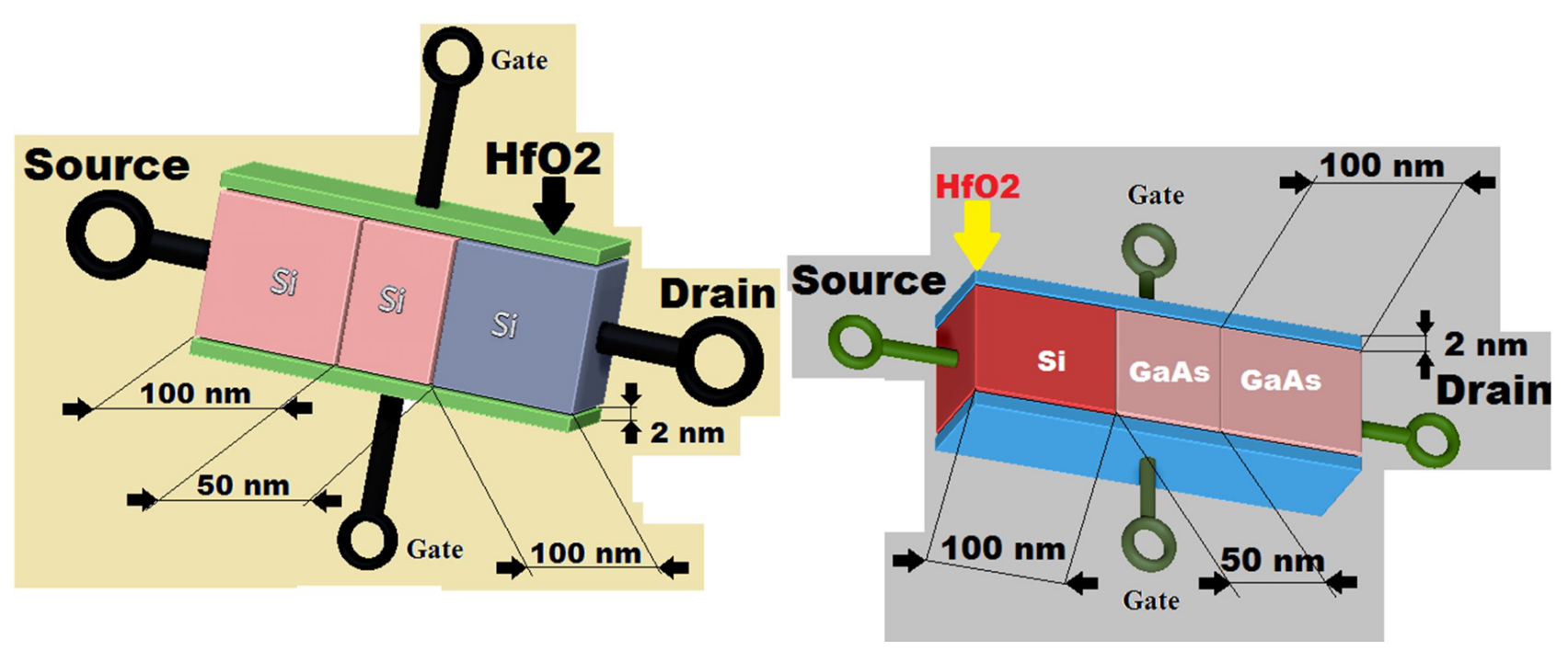

Figure 1: 3 D schematic homo and double tunnel FET. 


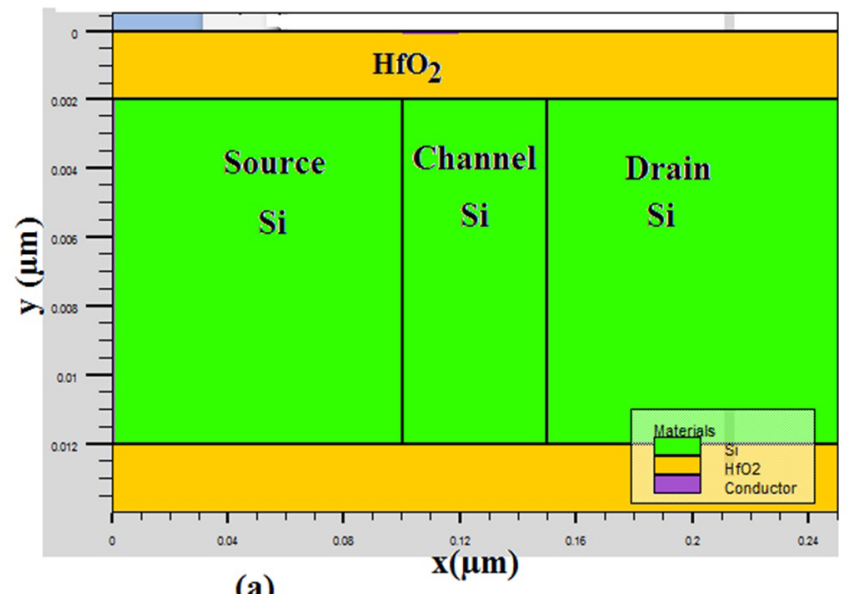

(a)

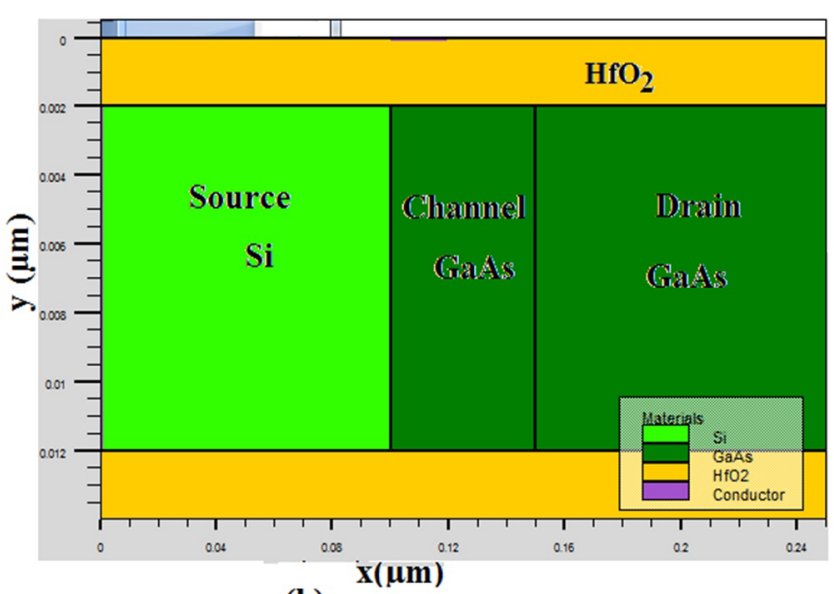

(b)

Figure 2: Tony plot display using 2D mesh of double gate (homostructure (a), heterostructure (b)).

Table 1: Design Parameters for Simulation double gate TFET.

\begin{tabular}{|l|l|l|}
\hline Parameters & Nomenclature & Numerical value \\
\hline$\phi M$ & Work function $(\mathrm{eV})$ & 5.2 \\
\hline$N_{S}$ & Doping levels for source $\left(\mathrm{cm}^{-3}\right)$ & $1.1 \times 0^{20}$ \\
\hline$N_{D}$ & Doping level for Drain $\left(\mathrm{cm}^{-3}\right)$ & $5.1 \times 0^{18}$ \\
\hline$N_{c}$ & Doping level for channel $\left(\mathrm{cm}^{-3}\right)$ & $10^{15}$ \\
\hline$t_{o x}$ & Gate oxide material thickness $(\mathrm{nm})$ & 2.0 \\
\hline$L_{t}$ & Total length of the device $(\mathrm{nm})$ & 250.0 \\
\hline$L_{c h}$ & Channel length $(\mathrm{nm})$ & 50.0 \\
\hline$t_{S i}$ & Silicon film thickness $(\mathrm{nm})$ & 10.0 \\
\hline$L_{s} / L_{D}$ & Source and drain lengths $(\mathrm{nm})$ & 100.0 \\
\hline
\end{tabular}

The channel material with intrinsic carrier concentration $\mathrm{n}_{\mathrm{i}}=1 \times 10^{15} \mathrm{~cm}^{-3}$, channel thickness $t_{\mathrm{si}}$ $=10 \mathrm{~nm}$ and channel length as in present research work. Figure $1 \mathrm{~b}$ having same device dimension and is structurally same as silicon TFET except GaAs is used on drain side and channel side. All the remaining device parameters and dimensions of hetero gate (hetro DG) TFET and homo gate (homo DG) TFET are listed in the Table 1 . The channel $\left(\mathrm{L}_{c h}\right)$ is 50 $n m$, source $\left(L_{s}\right)$ and drain lengths $\left(L_{d}\right)$ are $100 \mathrm{~nm}$. The gate oxide material thickness $\left(\mathrm{t}_{\mathrm{ox}}\right)$ is $2 \mathrm{~nm}$ and the silicon film thickness $\left(t_{\mathrm{si}}\right)$ is $10 \mathrm{~nm}$. The doping levels for source, channel, and drain regions are 1 $\times 10^{20}, 1 \times 10^{15}$, and $5 \times 10^{18} \mathrm{~cm}^{-3}$, respectively. The gate contact work function was set to be $5.2 \mathrm{eV}$.

All simulations of the DG-TFET, shown in Figure 1, Figure $2 a$ and Figure $2 b$ design have been carried out using Silvaco/ATLAS device simulator version 3.1.20.1. $R$ in windows 7 operating system environment. The non-local BTBT model (BBT.NONLOCAL) was utilized. Fine meshing tunneling in the regions where BTBT mainly takes place were defined. Mesh size $=5 \times 10^{-4} \mu \mathrm{m}$ at interface source/channel and mesh size $=10^{-3} \mu \mathrm{m}$ far of interface. The Newton's numerical method based on iteration was chosen to obtain a better convergence (CV). Further, to plot the figures of the high-frequency performance, a small-signal AC analysis was performed at a frequency of $1 \mathrm{MHz}$. The values adjusted to have the convergence for electron effective mass $\left(m_{e}\right)$ and hole effective mass $\left(m_{h}\right)$ used in the simulation are summarized on Table 2.

Current conduction in TFET is governed by bandto-band (B2B) tunneling between valence bands of source to conduction band of channel. This B2B tunneling is much more sensitive to material/device parameters such as energy bandgap $\left(E_{G}\right)$, dielectric thickness $\left(t_{o x}\right)$, gate-dielectric materials $(k)$, effective mass of charge carriers $\left(m^{*}\right)$ of tunnel devices, followed by Eq.1. The position of the valence and conduction bands of the intrinsic part changes with the applied gate voltage. A conduction path by 
Table 2: Listed parameters used in Si/Si/Si and Si/GaAs/ GaAs DG-TFET.

\begin{tabular}{|l|l|l|}
\hline \multirow{2}{*}{ Parameter } & \multicolumn{2}{l|}{ Materials } \\
\cline { 2 - 3 } & Si & GaAs \\
\hline Energy Gap $\mathrm{E}_{\mathrm{G}}(\mathrm{eV})$ & 1.12 & 1.43 \\
\hline Effective electron mass $\mathrm{m}_{\mathrm{e}}$ & 0.12 & 0.067 \\
\hline Effective hole mass $\mathrm{m}_{\mathrm{p}}$ & 0.17 & 0.45 \\
\hline Mobility of electron $\mu_{\mathrm{n}}\left(\mathrm{cm}^{2} \cdot \mathrm{V}^{-1} \mathrm{~s}^{-1}\right)$ & 8500 & 1345 \\
\hline Mobility of hole $\mu_{\mathrm{p}}\left(\mathrm{cm}^{2} \cdot \mathrm{V}^{-1} \mathrm{~s}^{-1}\right)$ & 400 & 458 \\
\hline
\end{tabular}

tunnel band-to-band (B2B) tunneling mechanism is then opened. The electrons can thus pass from the valance band (VB) of the $p$ region to the conduction band $(\mathrm{CB})$ of the intrinsic region and a tunnel current circulates in the device (the transistor is then in the on-state). The on-current ION of a DG-TFET, in the tunnel band-to-band (B2B) tunneling mechanism is proportional to the transmission probability $T(E)$ of the electrons or holes by tunnel effect, which is written by mathematical expression 1.

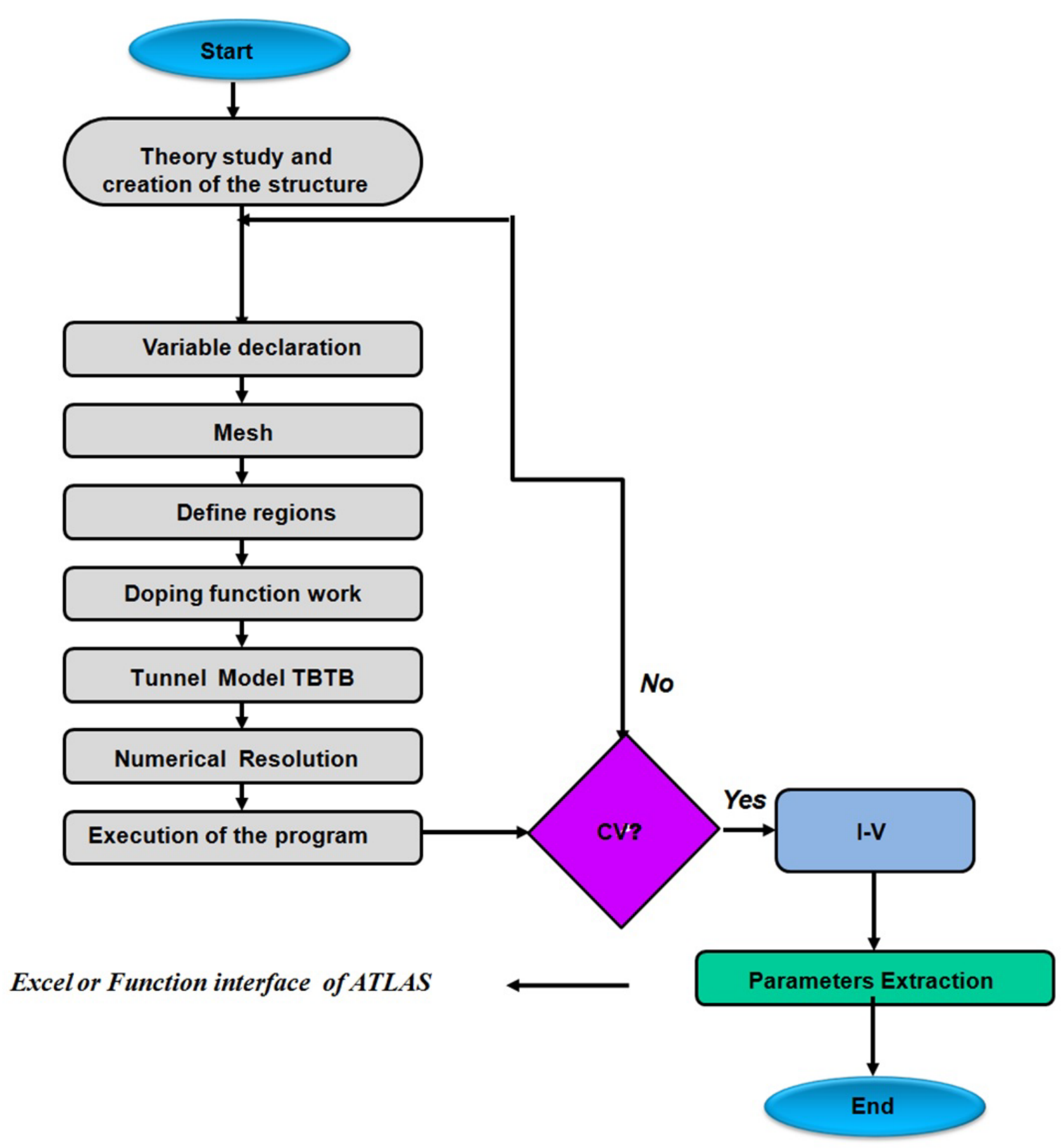

Figure 3: Atlas resolution algorithm of double gate TFET. 


$$
T(E) \approx \exp \left(-\frac{4 \lambda \sqrt{2 m^{*}} E_{g}^{3 / 2}}{3|e| \hbar\left(E_{g}+\Delta \phi\right)}\right.
$$

The tunneling distance $(\lambda)$ is determined by following mathematical expression (2). In Eq.1, m* is the effective mass and EG, is the band gap. The symbol $\lambda$ denote, the tunneling distance between the source and the channel, $\Delta \Phi$ denotes the band energy difference between the conduction band of source and valence band of the channel. The sym- bol $\hbar$, e denotes reduced Planck's constant and electronic charge respectively. While, the symbol $t_{o x}$ and $t_{s i}$ has been for physical oxide thickness, and semiconductor channel thickness respectively. The symbol $\varepsilon_{o x}$ and $\varepsilon_{s i}$ denote dielectric constants for oxide and silicon respectively [7].

$$
\lambda=\left(\sqrt{\frac{\varepsilon_{S i}}{\varepsilon_{o x}} t_{o x} t_{S i}}\right) \Delta \phi
$$

In this work, simulation is done using SILVACO

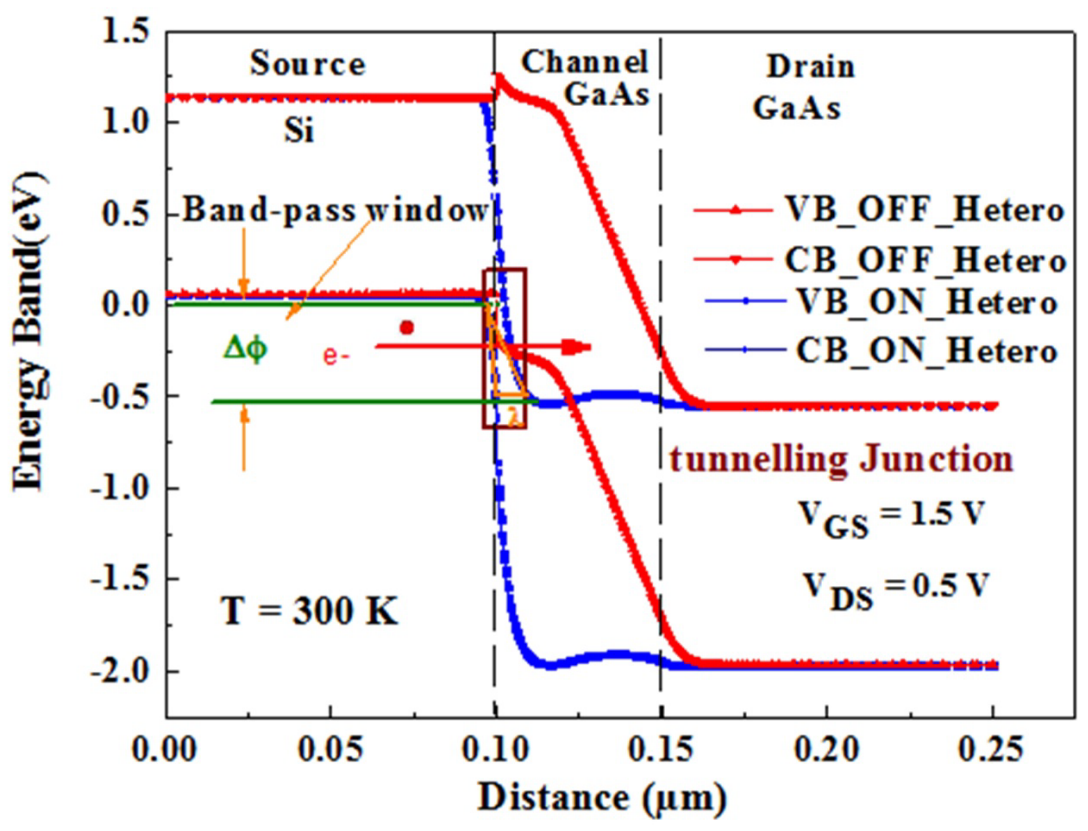

Figure 4: Energy band-diagram (OFF-State and ON-State) for hetero structure DG-TFET.

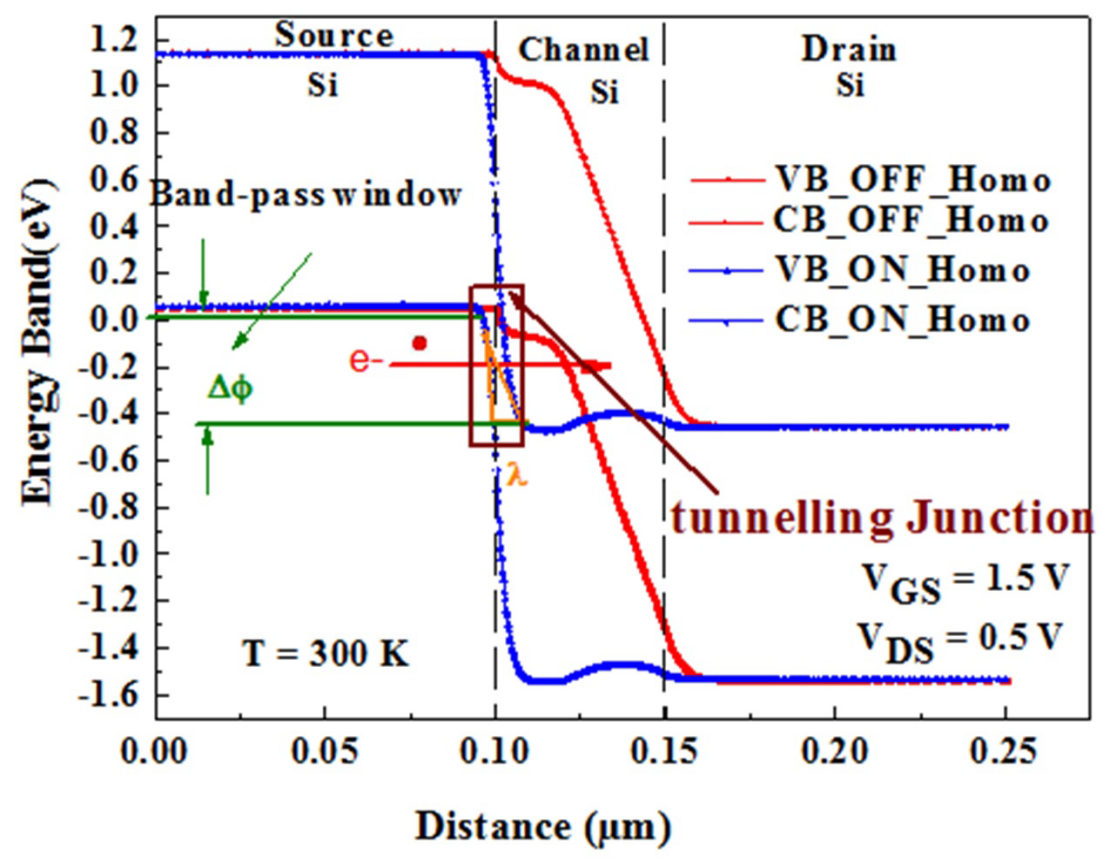

Figure 5: Energy band-diagram (OFF-State and ON-State) for homo DG-TFET. 
ATLAS. In the simulation non-local B2B Tunneling model is considered for the band to band tunneling of charge carrier between source and channel. Due to high doping of source band gap narrowing (BGN) model is also included, because effective bandgap directly influence the tunneling current. The Shockley-Read-Hall (SRH) recombination model have been due to the presence of high impurity atom in the channel and Fermi Dirac statistics for calculating intrinsic carrier concentration. For more accurate current calculation Schenk's Trap assisted Tunneling (TAT), drift-diffusion current transport model, and Quantum Confinement (QC) models are also included. Figure 3 represent the flow chart for present research work.

Figure 4 and Figure 5 show the energy band diagram of DG -TFET. As shown in Figure 4 and Figure 5 , when VGS $=0.0 \mathrm{~V}$, the device is in off-state with large tunnel barrier width $\lambda$, and therefore the charge carrier, electrons do not have enough energy to move from the valance band of the source to the conduction band of the channel. On application of sufficiently high gate voltage (i.e. $V_{G S}=1.5$ $\mathrm{V}$ and $\mathrm{V}_{\mathrm{DS}}=0.5 \mathrm{~V}$ ), the width of tunneling barrier $\lambda$ is reduced significantly and the device switches to on-state.

When the device switched from, the off-state to the on-state, an increase in the electric field is observed [5]. It has been observed that the tunnel barrier, $\lambda$ decreases and there is a shift of the conduction band downwards. Thus, the gradual enhancement of the gate bias, VGS degrades the barrier width and causes an increased tunneling of carriers, indicated in Figure 4 and Figure 5. The simulation results indicate that, hetero double gate TFET, having smaller tunneling width $\lambda$. For hetero and homo structured double gate TFET, tunneling with $\lambda, 0.05 \mu \mathrm{m}$ and $0.056 \mu \mathrm{m}$ is obtained during simulation respectively.

\section{Result and Discussion}

The tunneling barrier width $\lambda$ has been reduced in case of heterostructure TFET due to lattice mismatch between $\mathrm{Si}$ and GaAs semiconductors at channel interface. This causes increment in tunneling current due induced stain in tunneling region. This results, the higher on-state current $\left(\mathrm{I}_{\mathrm{ON}}\right)$ as shown in Figure 6.

Figure 6 shows the transfer characteristic of DG -TFET shown in Figure 1. It has been observed from Figure 6 the comparision of transfer characteristics of homo and hetero structure DG -TFET.

From Figure 6 one can observed, the drain current, IDS increased rapidly with the drain voltage,

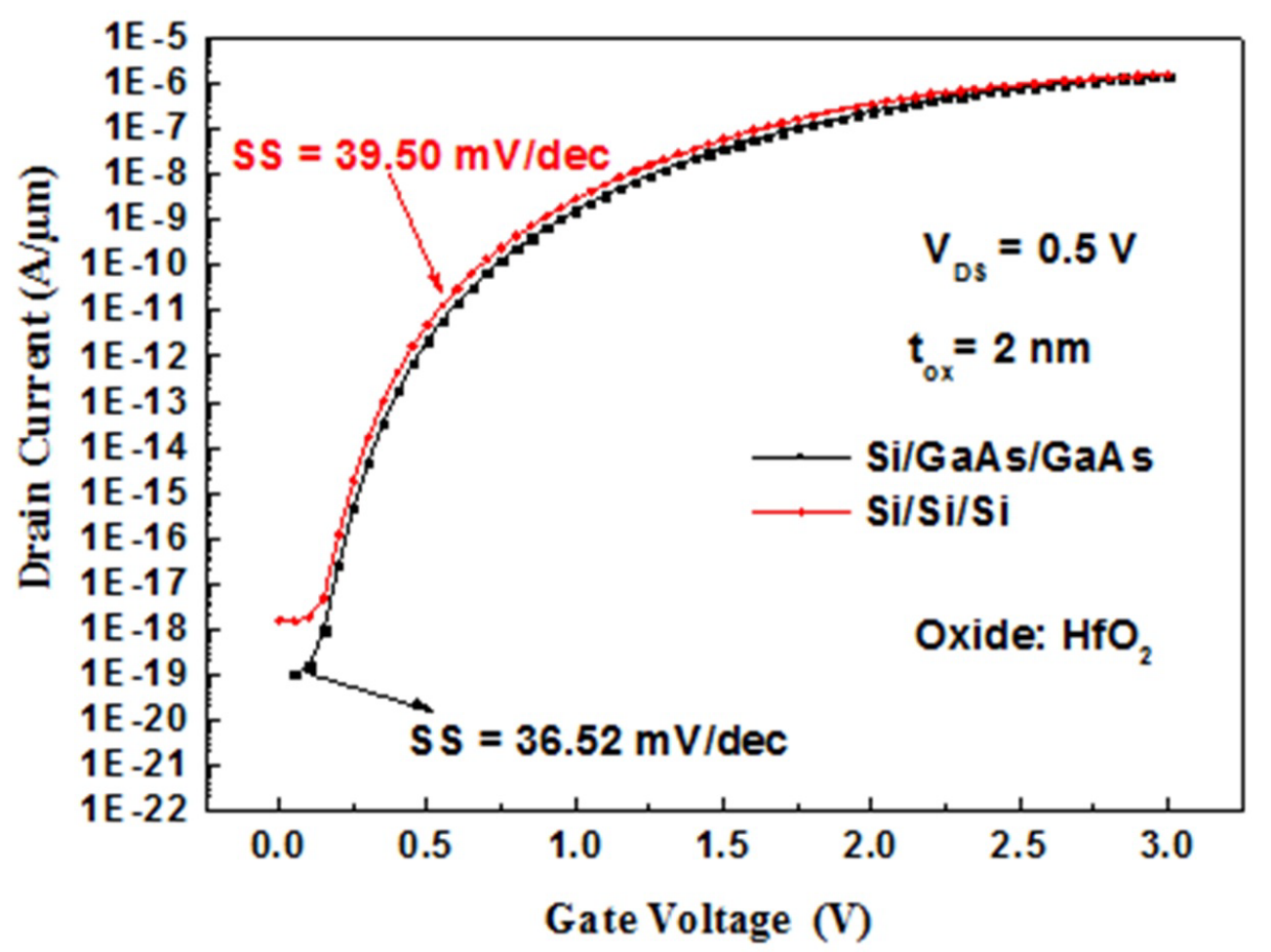

Figure 6: Comparision of transfer characteristics of homo and hetero structure double gate tunnel FET. 
VDS equal to $0.5 \mathrm{~V}$ the output current of hetero was higher than that the homostructure of the DG-TFET. Table 3, lists of the computed electrical parameters of the DG -TFET. As shown in Table 3 , various electrical parameters such as on-state (ION), off-state $\left(\mathrm{I}_{\mathrm{OFF}}\right)$, subthreshold slope (SS) and $\mathrm{I}_{\mathrm{ON}} / \mathrm{I}_{\mathrm{OFF}}$ ratio have improved. While ambipolarity current $\mathrm{I}_{\text {amb }}(\mathrm{A} / \mu \mathrm{m})$ has been reduced by order of $\sim 10^{8}$ times.

Figure 7 shows, the comparision of ambipolar property of homo and hetero structure DG-TFET. The result shows that, suppress the ambipolar current $\left(\mathrm{I}_{\mathrm{amb}}\right)$ without deteriorating analog, and transient performance. From Figure 7, It has been ob-

Table 3: Lists of the computed electrical parameters of the DG-TFET.

\begin{tabular}{|l|l|l|}
\hline \multicolumn{3}{|l|}{ Dielectric $\mathrm{HfO}_{2}$} \\
\hline $\begin{array}{l}\text { Electrical } \\
\text { Parameter }\end{array}$ & $\begin{array}{l}\text { Homo_DGTFET } \\
\text {-TFET }\end{array}$ & $\begin{array}{l}\text { Hetero_DG } \\
\text {-TFET }\end{array}$ \\
\hline $\mathrm{I}_{\mathrm{ON}}(\mathrm{A} / \mu \mathrm{m})$ & $4 \times 10^{-6}$ & $5 \times 10^{-6}$ \\
\hline $\mathrm{I}_{\text {ofF }}(\mathrm{A} / \mu \mathrm{m})$ & $10^{-18}$ & $1.1 \times 0^{-19}$ \\
\hline $\mathrm{I}_{\mathrm{ON}} / \mathrm{I}_{\mathrm{OFF}}$ & $4 \times 10^{12}$ & $5 \times 10^{13}$ \\
\hline $\mathrm{S}(\mathrm{mV} / \mathrm{dec})$ & 39,50 & 36,52 \\
\hline $\mathrm{I}_{\text {amb }}(\mathrm{A} / \mu \mathrm{m})$ & $5 \times 10^{-11}$ & $10^{-19}$ \\
\hline
\end{tabular}

served, with the help of 2-D. TCAD simulation that, the ambipolar current, $\mathrm{I}_{\text {amb }}$ is suppressed by $5.10^{8}$ order of magnitude in proposed $\mathrm{Si} / \mathrm{GaAs} / \mathrm{GaAs}$ hetero DGTFET as compared to Si/Si/Si homo DG -TFET up to the applied gate voltage of $\mathrm{V}_{\mathrm{GS}}=-3.0 \mathrm{~V}$ the step of gate voltage was taken equal to $0.5 \mathrm{~V}$. The computed electrical parameters of the both structures are listed in Table 3.

The transconductance $g_{m}$ represents amplification ability of device and it is defined as the slope of the transfer characteristic was used to evaluate the simulation performance of the device, the value of $g_{m}$ can be calculated by mathematical expression (3):

$$
g_{m}=\frac{d I_{D S}}{d V_{G S}}
$$

As shown in Figure 8 , the transconductance $g_{m}$ for both structures i. e. hetero and homo structures increase rapidly as external applied gate voltage $\mathrm{V}_{G S}$ increases. The maximum $g_{m}$ value of the hetero DG-TFET heterostructure is $1.6 \mu \mathrm{S} / \mu \mathrm{m}$ and the maximum $g_{m}$ value of the homo DG-TFET homostructure is $1.4 \mu \mathrm{S} / \mu \mathrm{m}$. The larger gm of hetero is larger than homostructure because the barrier width of tunneling junction decreases; the tunneling electrons increase (shown in energy band diagram Figure 4 and Figure 5). The transconductance

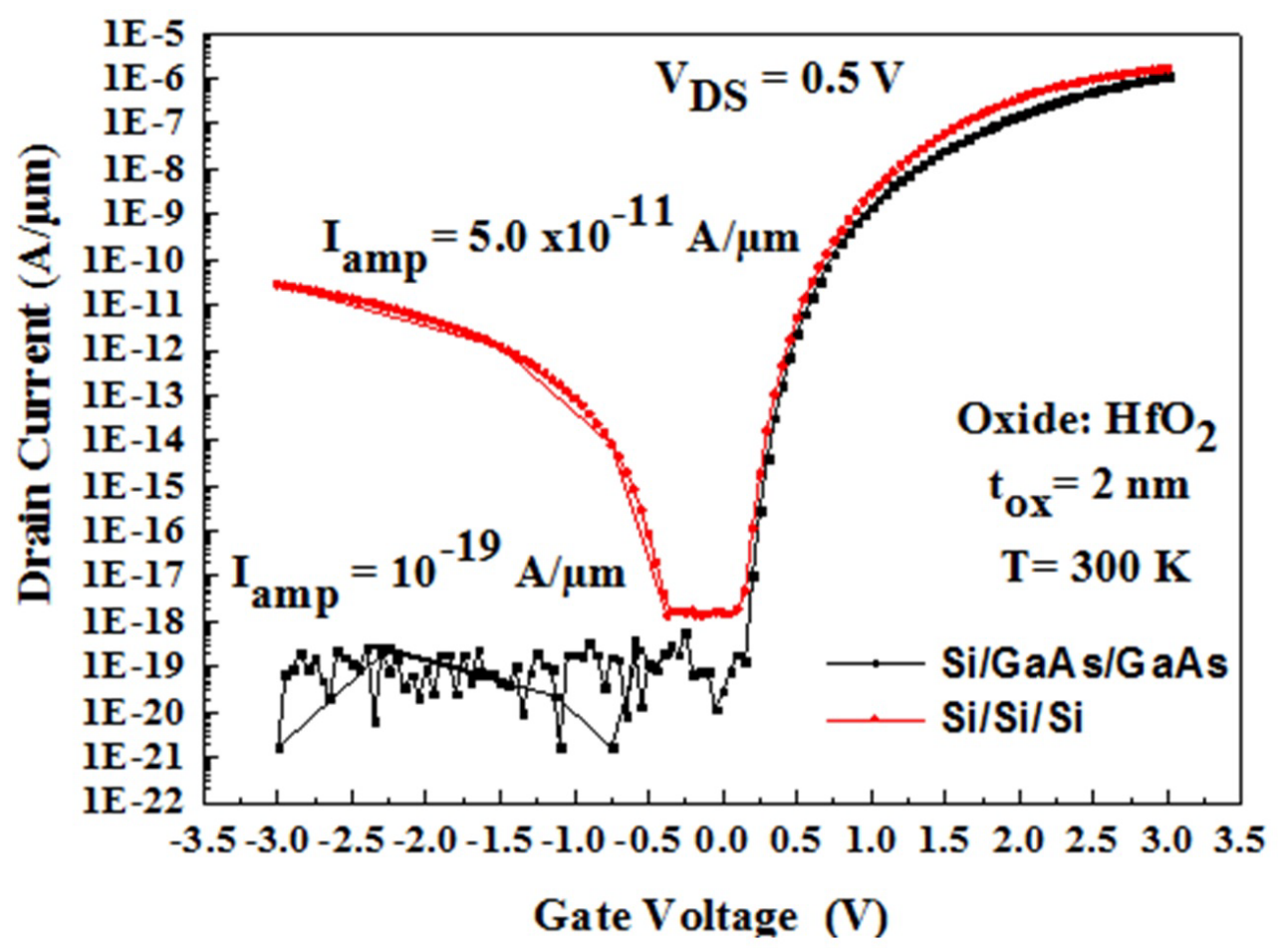

Figure 7: Comparision of ambipolar property of homo and heterostructure double gate tunnel FET. 


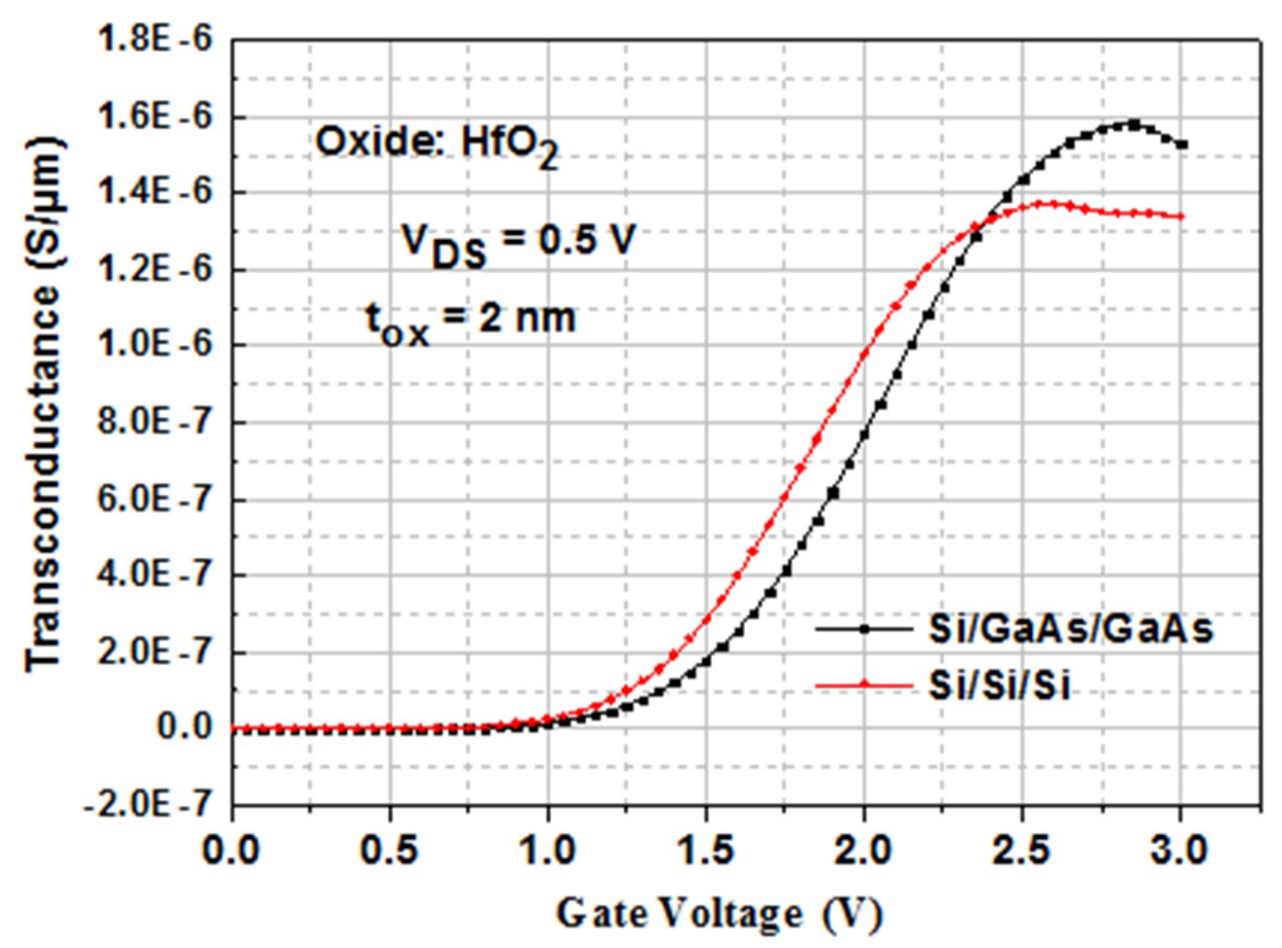

Figure 8: Comparision of transconductance of homo and heterostructure double gate tunnel FET.

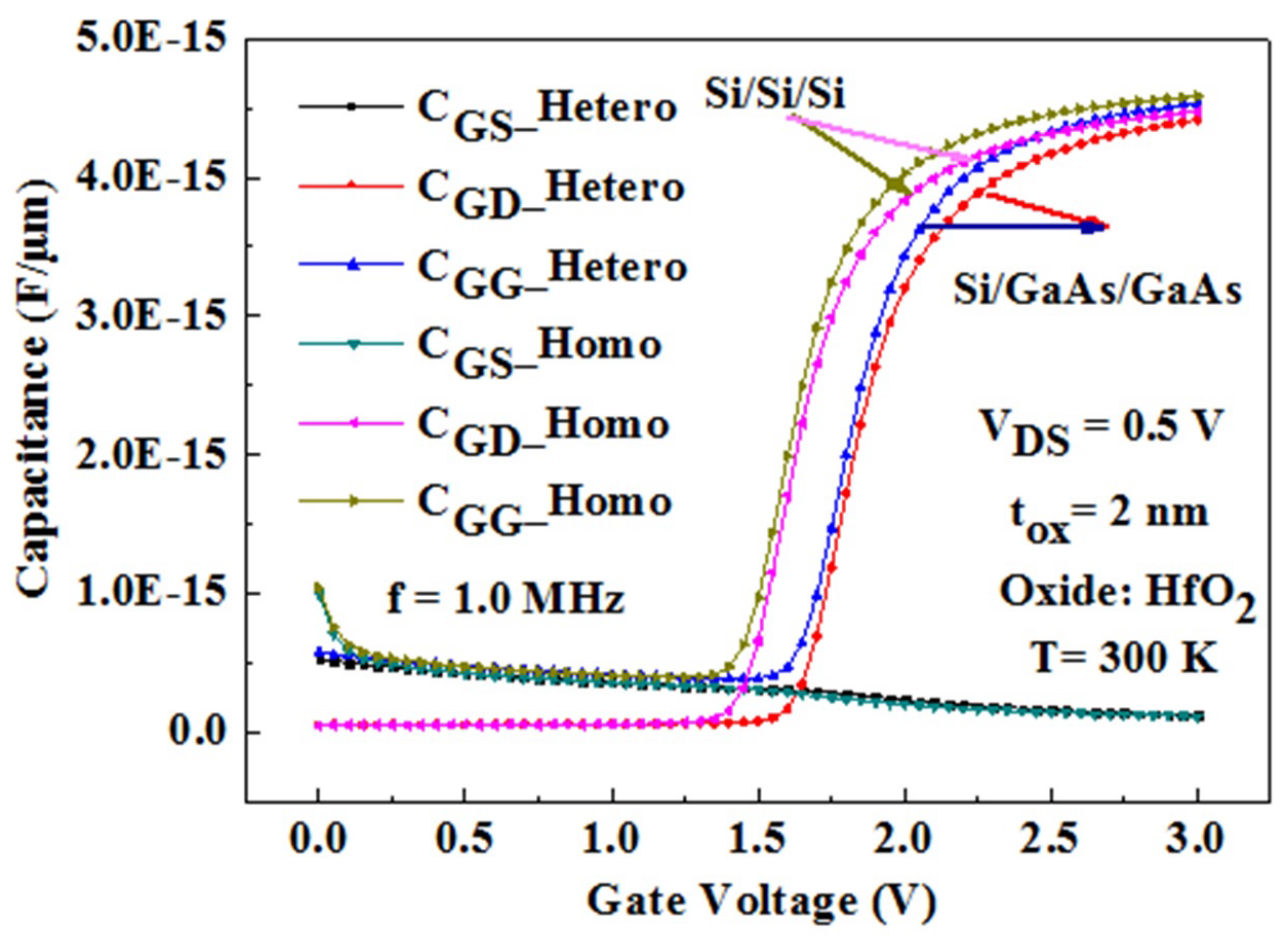

Figure 9: Comparision of C-V characteristics of homo and heterostructure double gate tunnel FET.

$\left(g_{m}\right)$ of a device depends on the value of drain current IDS. So, the drain current is higher for Si/GaAs/ GaAs DG - TFET compared to DG-TFET Si/Si/Si, due to the increase of tunneling volume in the channel.

Figure 9 shows the capacitance of different structure, as shown, an increase in the capacitance from bottom to top at the threshold voltage, The Gate-Gate capacitance is mainly composed of two capacitances Gate-Drain (Cgd) and Gate-Source (Cgs), Gate-Source capacitance is lower because 


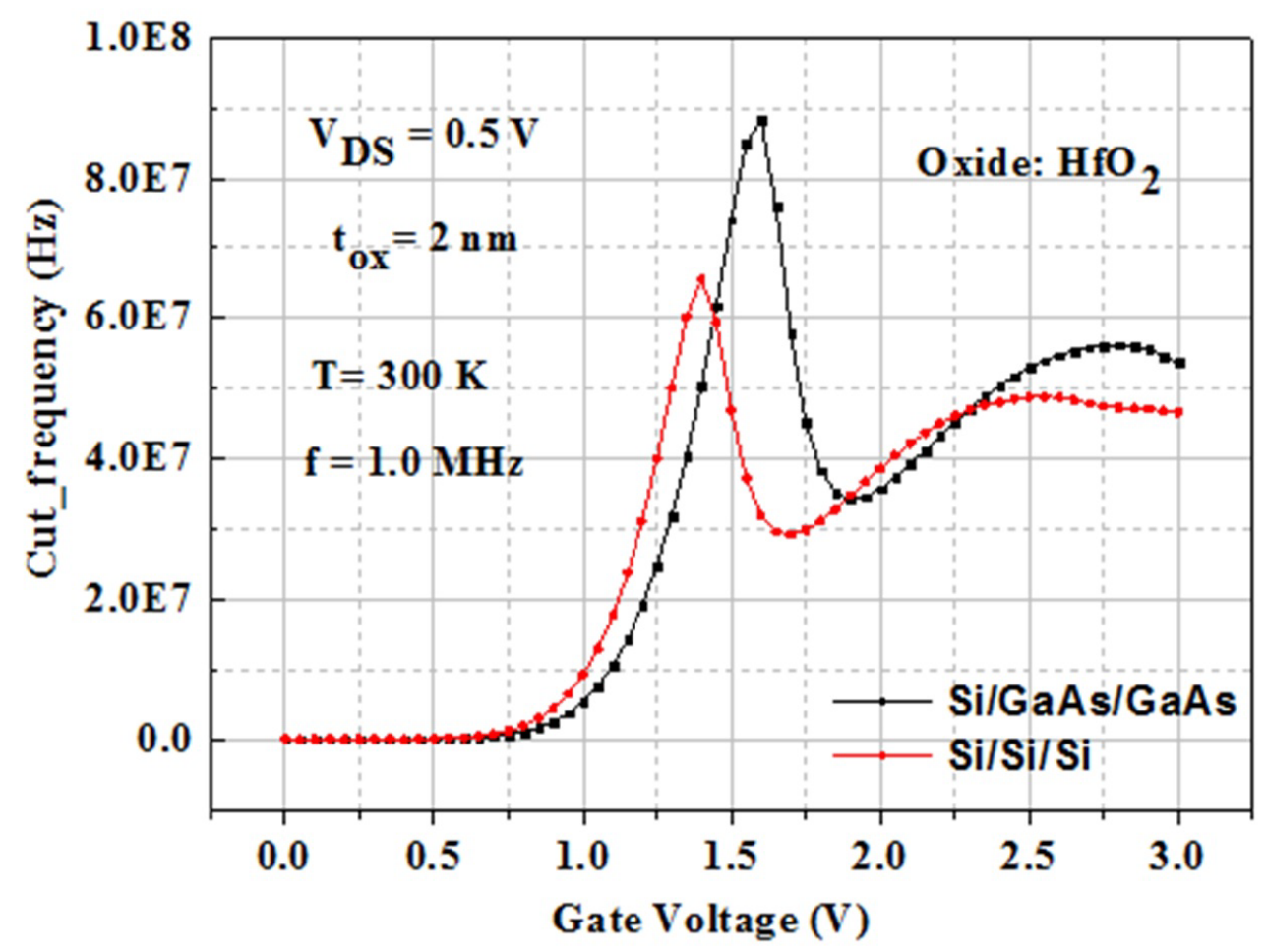

Figure 10: Comparision of cut-off frequency of homo and heterostructure double gate tunnel FET.

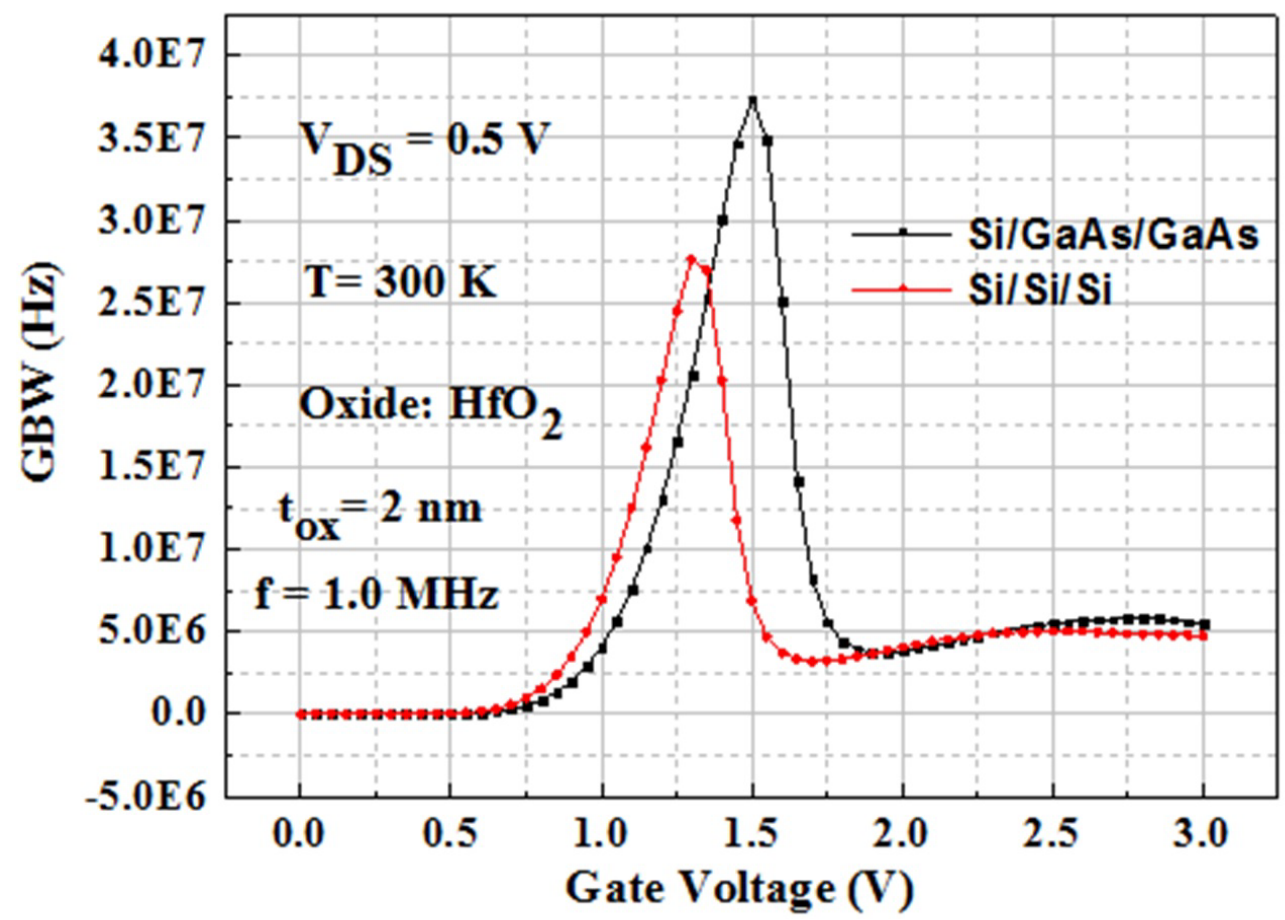

Figure 11: Comparision of gain band width (GBW) of homo and heterostructure double gate tunnel FET.

the presence of the tunnel effect, the Gate-Drain capacitance is a dominant capacitance due to the accumulation of the electrons of the Canal-Source and collected by the Drain region.

As an important indicator, the cut-off frequency is used to evaluate the frequency characteristics of electronic devices. It can be obtained by the ratio of $g_{m}$ to Cgg, with following relation, equation 4.

$$
f_{T}=\frac{g_{m}}{2 \pi\left(C_{g s}+C_{g d}\right)}=\frac{g_{m}}{2 \pi C_{g g}}
$$


In Figure 10, as the gate voltage increases, the the cut-off frequency $f_{T}$ increases to reach its maximum, then with increasing Cgg it goes down, when the gate voltage $\mathrm{V}_{G S}$ reaches $2.0 \mathrm{~V}$ the cut off frequency becomes constant. This is because the on-state current and gm value increase with the electronic B2B tunneling, the cut-off frequency of Hetero is much larger than that of homo, which can be explained by the smaller Cgg of hetero structure DG-TFET and the larger of the gm value. Table 4 resume values of $f_{\mathrm{T}}$ for both structures. This observation is verified in Figure 11 that show gain band width versus gate voltage $\mathrm{V}_{G S}$. It has been observed that, the simulation results predicts decreased gate capacitance with decreased operating voltage $\mathrm{V}_{\mathrm{GS}}$ as depicted in Figure 9 which gives the variation of the gate capacitance with $\mathrm{V}_{G S}$. It is should be noted that, the capacitances of TFET is bias-dependent. That is to say, the decrement rate of the gate capacitance with frequency is bias-dependent.

The gain bandwidth product (GBW) is anoth-

Table 4: Cut off frequency values for double gate TFET.

\begin{tabular}{|l|l|l|}
\hline High-k gate & \multicolumn{2}{|l|}{ Cut-off frequency } \\
\hline Dielectric $\mathrm{HfO}_{2}$ & $\mathrm{~V}_{\mathrm{DS}}=0.5 \mathrm{~V}$ & $\mathrm{~V}_{\mathrm{DS}}=2 \mathrm{~V}$ \\
\hline Hetero structure & $\sim 0.1 \mathrm{GHz}$ & $3 \mathrm{GHz}$ \\
\hline Homo structure & $\sim 65 \mathrm{MHz}$ & $1.4 \mathrm{GHz}$ \\
\hline
\end{tabular}

er important indicator in the analysis of frequency characteristics, which can be calculated by the equation 5 .

$$
G W B=\frac{g_{m}}{2 \pi 10 C g d}
$$

Another important performance parameter for $\mathrm{RF}$ analysis is transit time given by expression (6). According to this mathematical expression, time is inversely proportional to the cut-off frequency. If the cut-off frequency increases the transition time decreases. As a result, the speed of the heterojunction DG-TFET structure is better than that of homojunction DG-TFET, estimated cut-off frequency is smaller. Figure 12 shows the delay time versus gate applied gate voltage. From Figure 12, it can be observed that, the simulation results predicts increased delay time with increased operation gate voltage VGS. It is should be noted that the delay time is bias-dependent.

That is to say, the decrement rate of the gate voltage $\mathrm{V}_{\mathrm{GS}}$ with hetero gate double DG-TFET with smaller delay time than homo structure DG-TFET. The delay time of $\mathrm{V}_{\mathrm{GS}}=2.0 \mathrm{~V}$ decreases rapidly.

$$
\tau_{d}=\frac{1}{2 \pi f_{T}}
$$

It can be observed that, the simulation results predicts increased power delay product (PDP) with

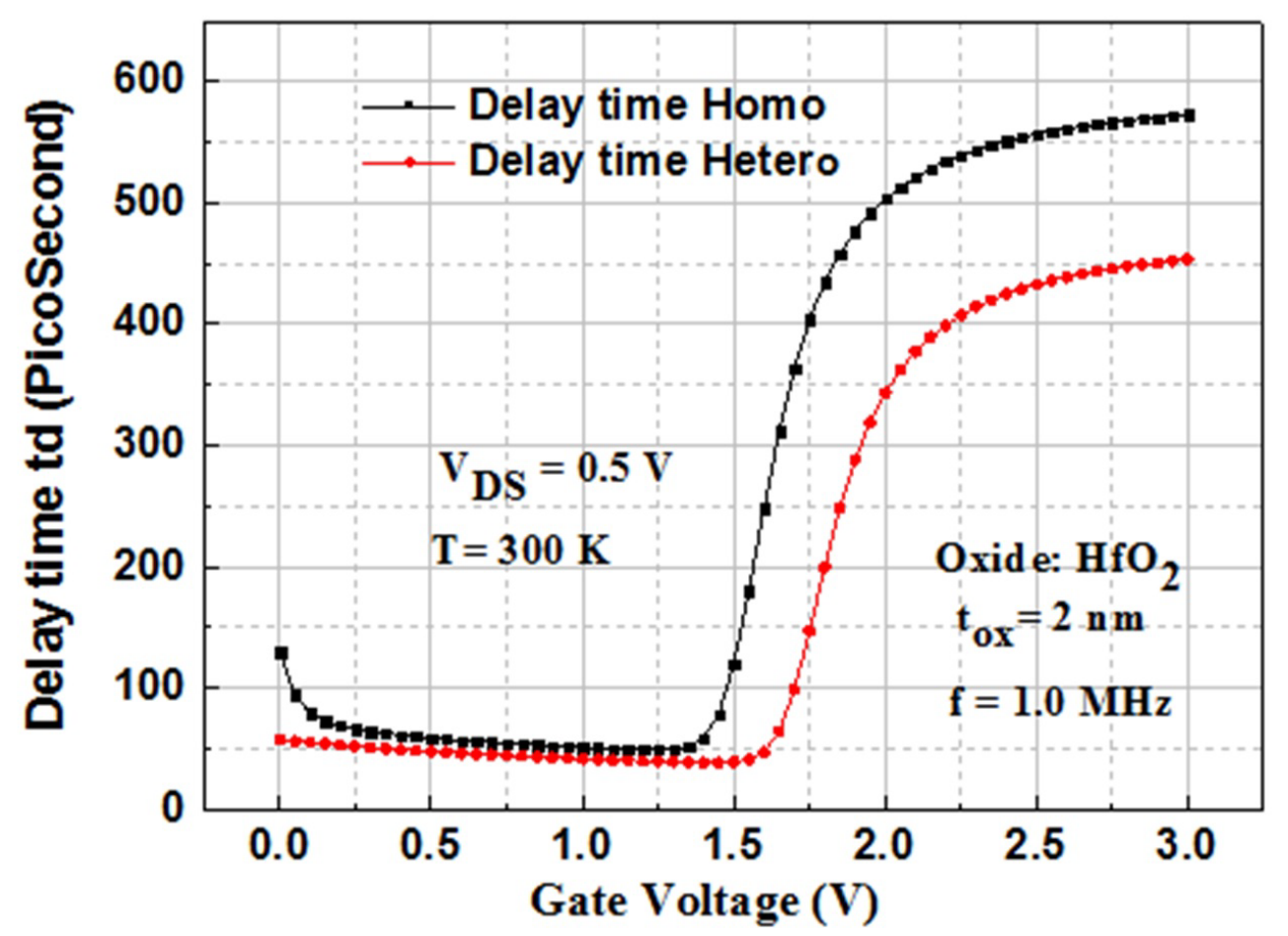

Figure 12: Comparision of delay time of homo and heterostructure double gate tunnel FET. 


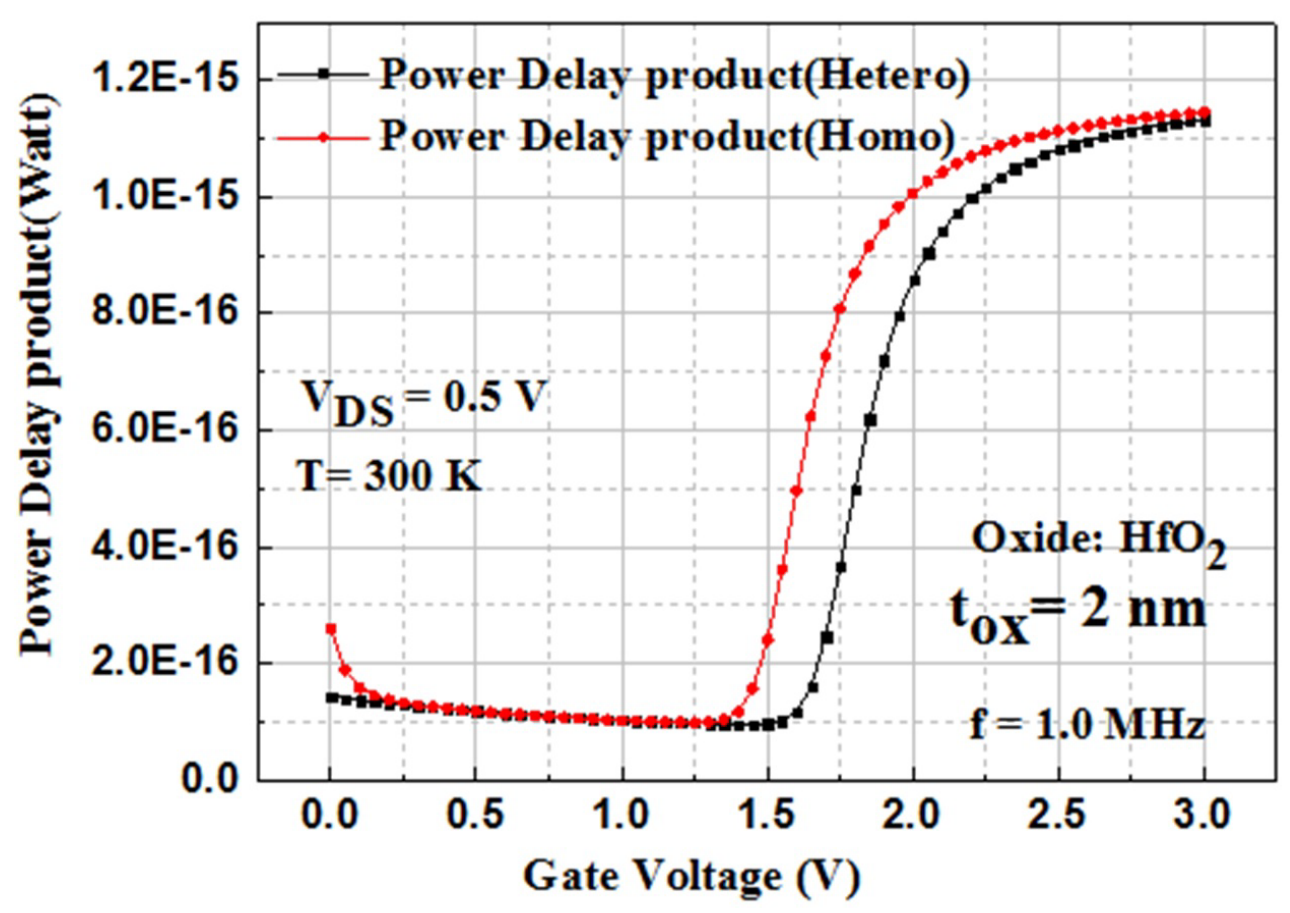

Figure 13: Comparision of Power delay product (PDP) of homo and heterostructure double gate tunnel FET.

increased operation gate voltage $\mathrm{V}_{G S^{\prime}}$ as depicted in Figure 13, which gives the variation of the power delay product (PDP) with gate applied gate voltage $V_{G S}$. It is should be noted that, the power delay product is bias-dependent. That is to say, the decrement rate of the gate voltage with hetero gate double gate with smaller power delay product (PDP). The delay time of $\mathrm{V}_{\mathrm{GS}}=2.0 \mathrm{~V}$ decreases rapidly.

\section{Conclusion}

In the present work, 2-D TCAD Silvaco simulations are used to study the impact of heterojunction on the DC, analog and PDP. In the adopted double gate TFET design achieved on-state current of $5 \times 10^{-6} \mathrm{~A} / \mu \mathrm{m}, \mathrm{I}_{\text {ofF }}$ of $1 \times 10^{-13} \mathrm{~A} / \mu \mathrm{m}$, SS of $\sim 36$ $\mathrm{mV} /$ decade, and maximum cut off frequency in the game of the RF also a very weak power delay product about of $1.1 \times 10^{-15}$ Watt. Also the value of delay time $t_{d}$ reach is obtained in picoseconds range ( 600 Picoseconds). By using, heterojunction DGTFET structure, it have observed the suppression of the ambipolar current $\mathrm{I}_{\mathrm{amb}} \sim 10^{8} \mathrm{~A} / \mu \mathrm{m}$ times. The advantageous results obtained for the proposed design show its usability in the field of digital and analog applications. These results are crucial for enabling a full and accurate assessment of TFETs through circuit predictions.

\section{References}

1. D Ghosh (2018) Nanoscale tunnel FETs for internet-of-things applications. IEEE Sensors, New Delhi, India, 1-4.

2. R Trivedi, S Carlo, S Mukhopadhyay (2013) Exploring tunnel-FET for ultra low power analog applications: A case study on operational transconductance amplifier. $50^{\text {th }} \mathrm{ACM} / \mathrm{EDAC} / \mathrm{IEEE}$ Design Automation Conference (DAC), Austin, TX, USA, 1-6.

3. T Krishnamohan, D Kim, S Raghunathan, K Saraswat (2008) Double-Gate strained-Ge heterostructure tunneling FET (TFET) with record high drive currents and $\ll 60 \mathrm{mV} /$ dec subthreshold slope. IEEE International Electron Devices Meeting, San Francisco, CA, 1-3.

4. Yu J, Kim S, Ryu D, Lee K, Kim C, et al. (2019) Investigation on ambipolar current suppression using a stacked gate in an L-shaped tunnel field-effect transistor. Micromachines (Basel) 10: 753.

5. M lonescu, H Riel (2011) Tunnel field-effect transistors as energy efficient electronic switches. Nature 479: 329-337.

6. J Bizindavyi, AS Verhulst, D Verreck, B Sorée, G Groeseneken (2019) Large variation in temperature dependence of band-to-band tunneling current in tunnel device. IEEE Electron Device Letters 40: 1864-1867.

7. SB Rahi, Bahniman Ghosh (2015) High-k double gate junction less tunnel FET with tunable bandgap. RSC Advances 5: 54544-54550. 
8. N Guenifi, SB Rahi, T Ghodbane (2018) Rigorous study of double gate tunneling field effect transistor structure based on silicon. Materials Focus 7: 1-7.

9. H Lu, A Seabaugh (2014) Tunnel field-effect transistors: State-of-the-Art. IEEE Journal of the Electron Devices Society 2: 44-49.

10.WY Choi, BG Park, JD Lee, TJK Liu (2007) Tunneling field-effect transistors (TFETs) with subthreshold swing (SS) less than $60 \mathrm{mV} / \mathrm{dec}$. IEEE Electron Device Letters 28: 743-745.

11.M Haris, SA Loan, Mainuddin (2017) An ambipolar immune Si/GaAs hetero-junction doping less TFET. International conference on Microelectronic Devices, Circuits and Systems (ICMDCS), Vellore, India, 1-4.

12.X Wang, Z Tang, L Cao, J Li, Y Liu (2019) Gate field plate structure for subthreshold swing improvement of Si line-tunneling FETs. IEEE Access 7: 100675100683.

13.SB Rahi, Bahniman Ghosh, Bhupesh Bishnoi (2015) Temperature effect on hetero structure junctionless tunnel FET. Journal of Semiconductors 36: 034002.

14.S Joshi, PK Dubey, BK Kaushik (2019) A transition metal dichalcogenide tunnel FET-based waveguide-integrated photodetector using Ge for near-infrared detection. In IEEE Sensors Journal 19: 9187-9193.

15.T Nirschl, Peng-Fei Wang, W Hansch, D Schmitt-Landsiedel (2004) The tunnelling field effect transistors (TFET): The temperature dependence, the simulation model, and its application. IEEE International Symposium on Circuits and Systems (IEEE Cat. No.04CH37512), Vancouver, BC, Canada.

16.Peng-Fei Guo, Li-Tao Yang, Yue Yang, Lu Fan, GenQuan Han, et al. (2009) Tunneling field-effect transistor: Effect of strain and temperature on tunneling current. IEEE Electron Device Letters 30: 981-983.

17.PG Der Agopian, JA Martino, R Rooyackers, A Vandooren, E Simoen, et al. (2013) Experimental comparison between trigate $\mathrm{p}$-TFET and $\mathrm{p}$-FinFET analog performance as a function of temperature. IEEE Transactions on Electron Devices 60: 2493-2497.

18.T Nirschl (2004) The tunneling field effect transistor (TFET) as an add-on for ultra-low-voltage analog and digital processes. IEDM Technical Digest. IEEE International Electron Devices Meeting, San Francisco, CA, USA, 195-198.

19.K Tomioka, A Yoshida, H Gamo (2019) Heteroepitaxial growth of InGaAs/InP/InAlAs/InP core-multishell nanowires on Si for a complementary tunnel FETs. Compound Semiconductor Week (CSW), Nara, Japan, 1-1.
20.N Sharma, SS Chauhan (2017) Steep subthreshold swing analysis of dual metal drain dopingless double gate tunnel FETs based on ge-source with high-k for low power applications. International Conference on Computing, Communication and Automation (ICCCA), Greater Noida, India, 1445-1448.

21.K Boucart, AM Ionescu (2007) Double-Gate tunnel FET with high-K gate dielectric. IEEE Transactions on Electron Devices 54: 1725-1733.

22.SB Rahi, P Asthana, S Gupta (2017) Heterogate junctionless tunnel field-effect transistor: Future of low-power devices. Journal of Computational Electronics 16: 30-38.

23.Pranav Kumar Asthana, Bahniman Ghosh, SB Rahi, Yogesh Goswami (2014) Optimal design of high performance $\mathrm{h}$-jltfet using $\mathrm{HfO} 2$ as gate dielectric for ultra low power applications. RSC Advances 4: 2280322807.

24.B Lu, Z Lv, H Lu, Y Cui (2019) A Non-Quasi-Static model for tunneling FETs based on the relaxation time approximation. IEEE Electron Device Letters 40: 1996-1999.

25.MC Robbins, P Golani, SJ Koester (2019) Right-Angle black phosphorus tunneling field effect transistor. IEEE Electron Device Letters 40: 1988-1991.

26.M Ehteshamuddin, SA Loan, AG Alharbi, AM Alamoud, M Rafat (2019) Investigating a dual MOSCAP variant of Line-TFET with improved vertical tunneling incorporating FIQC effect. IEEE Transactions on Electron Devices 66: 4638-4645.

27.G Musalgaonkar, S Sahay, RS Saxena, MJ Kumar (2019) Nanotube tunneling FET with a core source for ultrasteep subthreshold swing: A simulation study. IEEE Transactions on Electron Devices 66: 4425-4432.

28.S Tayal, A Nandi (2017) Analog/RF performance analysis of channel engineered high-K gate-stack based junctionless Trigate-FinFET. Superlattices and Microstructures 112: 287-295.

29.K Vanlalawpuia, B Bhowmick (2019) Investigation of a Ge-Source vertical TFET with Delta-Doped layer. IEEE Transactions on Electron Devices 66: 44394445.

30.Kumar (2019) Performance evaluation of double gate tunnel FET based chain of inverters and 6-T SRAM cell. Engineering Research Express 1: 025055.

31.K Nagashio (2019) All solid-state 2D tunnel FET. Compound Semiconductor Week (CSW), Nara, Japan, 2019: 1-1.

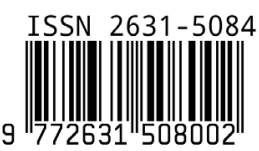

